\section{Synthetic ivory fails to stop illegal trade}

Synthetic ivory can now be crafted to the same diagnostic standards as genuine ivory (see M. E. Sims et al. Ethnobiol. Lett. 2, 40-44; 2011), and its price in China is only about $14 \%$ of that of real ivory. First manufactured in 1865 to save elephants' tusks from being turned into billiard balls (US patent 50359), synthetic ivory is not proving to be the panacea hoped for by conservationists and Chinese enforcement agencies.

Because synthetic and authentic ivory are so similar, unscrupulous traders caught smuggling illegal ivory can claim that it is synthetic; they can also pass off synthetic ivory as genuine when they sell it. The situation may be aggravated by legitimate traders, because they are entitled to compensation if destructive sampling is carried out to conclusively distinguish real from synthetic ivory (H. G. M. Edwards and D. W. Farwell Spectrochim. Acta A 51, 2073-2081; 1995).

One of us (Z.-M. Z.), as an enforcement officer for the Yunnan Public Security Bureau for Forests in China, has investigated 57 cases of suspected illegal ivory trading since 2011. Of these, 27 attempted to disguise samples of genuine ivory by mixing them with fake ivory, and only 513 of 1,714 items actually proved to be synthetic. These litigants all voluntarily submitted their products to destructive sampling, saying that they were deceived by their own suppliers.

The illegal ivory trade does not seem to be diminishing: in November 2013 alone, for example, customs agents in Xiamen, China, seized around 12,000 kilograms of imported ivory, and three Chinese citizens were arrested for smuggling $1,800 \mathrm{~kg}$ of ivory from Tanzania. Zhao-Min Zhou* Yunnan Public Security Bureau for
Forests, Kunming, China. zhouzm81@gmail.com

${ }^{\star}$ On behalf of 4 co-signatories; see go.nature.com/prbm3o for full list.

\section{GDP: signposting a false choice}

Robert Costanza and colleagues suggest that it is time to abandon gross domestic product (GDP) as a measure of national success (Nature 505, 283-285; 2014). However, I feel that your choice of an illustration of a signpost to make this point conveys the wrong message - namely, that we must decide between economic growth and sustainable progress.

The authors' point is that GDP growth does not equate to economic growth: it is a measure of currency transactions but not of net value creation. Economic growth, properly considered, is an increase in net value produced and a rise in capital assets that can be used for value production.

Modern scientific thinking classes natural ecosystems as capital assets, so we should include the protection of ecosystems as value production and the destruction of ecosystems as value depletion. Likewise, improvements in social systems and general social well-being create value.

The genuine progress indicator (GPI) incorporates economic growth as defined in these terms, so there is no dichotomy: the signposts should be pointing in the same direction.

Bryan Long Palo Alto, California, USA. bryan@econosystemics.com

\section{GDP: no one metric can rule them all}

Robert Costanza and colleagues call for the development of an alternative metric that includes a broader set of information than gross domestic product (GDP) and better reflects human wellbeing (Nature 505, 283-285; 2014). Improved metrics are needed, but we believe that more understanding is gained from balancing many related metrics.

The authors tell a common story of too much reliance on a single metric and too little attention to its shortcomings as it shapes our world view and influences behaviour. For instance, current US political discussion is heavily focused on a 'jobs' metric, which also conveys an incomplete, and often misleading, message. As with GDP, this metric does not distinguish between activities that help or hurt well-being, and it does not offer much insight into social health and sustainability.

Individually, metrics can mislead and misdirect; in a set of complementary metrics, they can provide invaluable knowledge. Composite metrics are useful, but embody weighted components that impose and conceal trade-offs that should be understood and discussed.

Ironically, as we increasingly understand the complexities of how the world works, policymakers and the public want to distil this complexity into a single metric. Improving a metric is a step forwards; improving our use of metrics would be a leap forwards.

Gregg Marland, Todd L. Cherry, Howard S. Neufeld Appalachian State University, Boone, North Carolina, USA. marlandg@appstate.edu

\section{Addiction: many factors contribute}

Your assertion that drug addiction is a brain disease (Nature 506, 5; 2014) is a contentious oversimplification - akin to always blaming a car crash on the car alone.

By this analogy, addiction is the car crash and the brain is the vehicle: the person driving it contributes a psychological component, the others on the road represent social factors, and road conditions correspond to the environment. To promote any one of these as the prime cause of addiction, as in the brain-disease model, overlooks the importance of the other components.

There is a risk that such a reductionist biological view could hinder the development of solutions for addiction. It could also undermine a considered response to the issue of politically driven bans on the use of animals in addiction research - itself a topic that has important social, psychological and environmental contributors. John A. Cunningham Australian National University, Canberra, Australia. john.cunningham@anu.edu.au

\section{Addiction: not just brain malfunction}

Irrespective of the animal-rights issues you discuss, we disagree with your one-dimensional view that addiction is a disease, and with your claim that this view is not particularly controversial among scientists (Nature 506, 5;2014). Neuroscience has been widely documented as just one of many important influences in drug addiction.

Substance abuse cannot be divorced from its social, psychological, cultural, political, legal and environmental contexts: it is not simply a consequence of brain malfunction. Such a myopic perspective undermines the enormous impact people's circumstances and choices have on addictive behaviour. It trivializes the thoughts, emotions and behaviours of current and former addicts. It also belittles the significant effect that publichealth campaigns and legislation exert on curbing substance abuse.

Addiction is too complex to be fought on a medicalresearch front alone. A variety of approaches based on diverse levels of analysis is required.

Derek Heim ${ }^{*}$ Edge Hill University, Ormskirk, UK. heimd@edgehill.ac.uk ${ }^{*}$ On behalf of 94 co-signatories; see go.nature.com/ehujzh for full list. 